\title{
Feeling the city: migrant narratives and urban space
}

\author{
Ágnes Györke ${ }^{1}$ Eszter Timár ${ }^{2}$
}

Accepted: 3 September 2021 / Published online: 16 September 2021

(c) The Author(s), under exclusive licence to Springer Nature Limited 2021

Narratives of flight often depict cities and cities are often considered central to the imaginary of refugees. How is the city "felt" in these narratives and how do they portray the ways in which subjectivities are shaped in urban space? What is the role of public spaces and performances in staging narratives of colonial violence and displacement? How do the haunting returns of the traumatic past reverberate in these spaces? Exploring these questions in the context of Western colonialism and the Arab Spring, this special issue offers four studies that discuss the impact of colonialism and displacement on the formation of subjectivities in terms of race, ethnicity, and gender, among other factors. The aim of the issue is twofold: apart from focusing on the role cities play in staging sometimes multiple layers of contested traumatic memories, articles also investigate the significance of affect in intersubjective encounters set in urban locations. Literary works, theatrical performances, installations, and protest marches are analysed in an interdisciplinary framework, which foregrounds the diverse yet overlapping emotions that haunt urban narratives of colonial trauma and migration.

Following in the wake of Lisa Blackman, John Cromby, Derek Hook, Dimitris Papadopoulos, and Valerie Walkerdine, we define subjectivity as "the experience of the lived multiplicity of positionings" (Blackman et al. 2008, p. 6). The articles in the issue explore how subject positions are affected by the experience of colonialism and dislocatedness. Contributions focus on historical and social issues such as Paris and the massacre of Algerian protesters on October 17, 1961 (Christine Quinan); New York and the unseen experiences of illegal migrants (Aparajita Nanda); Malmö and its Community Theatre used for performing migrant narratives (Tegiye Birey); Leipzig and protest actions staged at its Main Station (Elisabeth Kirndörfer). The concept of the postcolonial city (McLeod 2004; Varma 2012), haunted by the colonial past and memories of violence, is central to Quinan's argument, while Nanda reads New York as a neocolonial metropolis where a new form of slavery prevails. Birey and Kirndörfer, on the other hand, explore how immigrants and refugees

Ágnes Györke

gyorke.agnes@kre.hu

1 Károli Gáspár University, Budapest, Hungary

2 Central European University, Vienna, Austria 
utilize public spaces in European cities to stage their own narratives. These performances aim to showcase unseen stories in central locations, which call attention to hidden forms of violence. Aiming to map the ways in which migrant subjectivities are positioned in urban space, then, all articles engage with narratives that subvert the centre/margin binarism and foreground new forms of translocal connectedness.

The concept of encounter is explored in at least three senses in the issue. First, intersubjective encounters are traced in the postcolonial city, which challenge stigmatized images of migrants as "strangers". Second, the encounter of past and present is mapped through the analysis of haunting, traumatic memories transmitted through artworks. This practice, which foregrounds the significance of reassembling memories in non-familiar ways, directly exposes the third kind of encounter the articles in this issue engage with: that of official, state-sanctioned narratives and alternative stories. The first sense, figuring the stranger, the other, the different-a figure which has been a major concern of postcolonial and psychoanalytic theories-gains heightened significance in the context of contemporary migration. As Sara Ahmed writes, "[t]hrough strange encounters, the figure of the 'stranger' is produced, not as that which we fail to recognise, but as that which we have already recognised as 'stranger'" (Ahmed 2000, p. 3). In Ahmed's reading, the stranger is both a figure construed to alleviate the fear of the unknown, a character produced by the media and political billboards, and a "reminder of differences we must celebrate" (ibid. p. 4). The articles in this issue expose these strategies: the close reading of migrant narratives discloses the demonized fear the image of the "stranger" evokes, yet contributors are also suspicious of the celebratory rhetoric of multiculturalism, staged as an ideal, "happy" encounter between East and West.

The concept of conviviality and its relevance in the context of multicultural theories is central to this argument. In Paul Gilroy's view, conviviality is an ability "to live with alterity without becoming anxious, fearful, or violent" (Gilroy 2004, p. xi). He offers the term as an alternative to multiculturalism, aiming to question the "empty, interpersonal rituals" (Gilroy 2004, p. xi) of official multicultural ideologies and advocate a genuine solidarity from below. Gilroy's concept of conviviality is based on the alleviation of negative affect, such as anxiety and fear, which contribute to the creation of the demonised "stranger" to a great extent. Understood as the capacity for people to live together peacefully while imagining themselves as sharing a space with several kinds of "others," convivial encounters counteract the stigmatization of migrant communities.

Gilroy's understanding of conviviality, to the extent that it makes sense to us as a kind of theoretical "good" worth cherishing (and we, the authors of this editorial, whole-heartedly subscribe to this) does so by orchestrating (at least) two conceptual nodes: the thought of the urban and affect. In other words, conviviality is the thought of non-violence in relation to postcolonial metropolitan affect. Conviviality in After Empire offers an answer to the question of how to think life "after" postcolonial trauma in the colonial centre. When we emphasize the significance of the city, it is not merely because it might necessarily refer to urban settings but also because the issue is concerned with necessary conceptual connections between the contemporary metropole and its history as an imperial centre. In the figure of the modern metropolis (in the centre and elsewhere), the notion of urban density permeates our 
ideas about multiculture and postcolonial trauma through the associated imagery of masses migrating in the wake of colonially induced ongoing theatres of violence, manifesting purportedly new conflicts along racial and ethnic lines of difference. These conflicts tend to be framed as arising from the problems of different cultures forced to endure a stressful, crowded proximity infused with a language of competition of "jobs." To the extent that the discourse of the city is always also the discourse of migration, colonialism marks, and to a significant degree, makes the modern city.

The second node of conviviality is affect: it invokes joyous togetherness. In this sense of joyousness, Gilroy's notion of conviviality also resonates with the development of the affective turn insisting on the significance of positive affect as part of a response to the linguistic turn's purported overemphasis on language, psychoanalysis, and trauma (Braidotti 2006). Nevertheless, as the articles in this issue showcase, the focus on conviviality does not mean that negative affect necessarily disappears from focus. Negative affect, an attention to the unsettling effects of fear, shame, anger, for instance, is an important resource for victims of violence in writing counter-narratives that expose unseen stories and feelings in the course of transforming oneself from victim to survivor, from oppressed other to peer.

Sustaining attention to negative affect is especially relevant in the postcolonial context: as Ana Dragojlovic points out, "affective politics can be intentionally mobilised in order to challenge silenced histories of abuse, violence, and shame" (Dragojlovic 2018, p. 91). Indisputably, negative affect such as shame, irritation, anger, anxiety, and depressive states accompany and confront colonial trauma, racism, and other forms of violence. According to Dragojlovic, these affects do not simply call attention to individual and collective injuries but actively contribute to challenging mainstream ideologies and seamless histories. Counter-archival practices, in fact, "insist on evoking negative or unhappy affect by engaging in embodied performances of human and non-human bodies, aiming to shock and surprise at the visceral level" (Dragojlovic 2018, p. 91). In a similar vein, Quinan's article in this issue explores Zineb Sedira's installation, Mother Father and I and Leila Sebbar's novel, The Seine Was Red as counter-archival narratives, which shed light on painful memories of violence. As Quinan demonstrates, artworks embracing affects such as sadness, anger, distress, surprise, and discomfort expose the emotional impact of intergenerational traumas and, due to the experimental communication they showcase, challenge official narratives of the Algerian war.

It is with regards to this theoretical tension between discussions of negative and positive affect that the articles in this issue present a productive elaboration of postcolonial metropolitan affect. In order to start explaining this in the detail it deserves, we need to return to the theoretical stakes inherent in emphasizing positive affect. We suggest that the etymology of "conviviality" lends itself to a proto-vitalist legacy as it joins the idea of feast and festivity and living together; the pleasure of eating, a figure of triumphant survival, imbues the image of happy togetherness in which there is no conceptual space for anxiety or fear, and evokes a world where violence only appears subsumed in the idea of masticating previously live matter. This is in great affinity with the Deleuzean-Spinozean attention to affect as represented in the works of Braidotti and Massumi, itself embracing the legacy of vitalism. The affective turn, however, included theoretical gestures never quite at ease with this 
kind of vitalism so prevalent otherwise. Attention to negative affect never entirely disappeared. The theoretical background of this special issue includes two important thinkers whose work, while not opposed to the thought of positive affect at all, shaped affect theory through a consistent attention to the productive forces of negative affect: Sara Ahmed and José Muñoz.

We already discussed the relevance of Sara Ahmed's concept of the stranger; at this point we also would like to refer to her work on the economies of affect (Ahmed 2004), in which she thinks about the affective politics inherent in the discourse of the nation, based on symbolic exclusion achieved through the language of fear and disgust. In Elisabeth Kirndörfer's article Ahmed's work is traced back to Kristeva's concept of abjection. The analysis of racially inflected national politics through a lens of affect, quite compatible with psychoanalytic theory across Ahmed's work, resonates strongly with a similar theoretical focus on race, national belonging and the development of psychoanalytically informed terms in the writings of José Esteban Muñoz on disidentification, utopia, and a sense of "feeling brown."

While these terms refer to different political arguments about queerness, race, national belonging and affect, they all spring forth from a background provided by an innovatively woven theoretical web of Marxist thought after Marx, a certain appreciation of psychoanalysis as a resource for political thought, and a consistent attention to Melanie Klein's work on the depressive position and love. The resulting work is very consistent in making sense of the social and the subjective without relying on the politics of identity: affect, in fact, is embraced by Muñoz, a rigorous thinker of the nation, because he thinks it facilitates political analysis on the connection between identification and multiracial national belonging without needing to posit anything as an essence. In his texts on "feeling down, feeling brown" Muñoz turns to Melanie Klein's work in order to suggest an affective resonance in Latinx cultures in the U.S., a resonance illuminated by a certain psychoanalytic attention to melancholia (exceeding the scope of narrow clinical purposes of normalization). Klein's work is important here because her argument on the depressive position suggests a crucial and constitutive link between the idea of depression conceived of as an affective palette developed in response to rage and loss and our subsequent individual edifice of identification including the capacity to love (and belong). Negative affect and responding to negative affect here is therefore crucial for Muñoz both for thinking political identification and utopia. Two of the articles in this issue work with Muñoz in a substantial way. Aparajita Nanda's text draws on his work on disidentification, a term that relies on the vocabulary of performance and identity to open up nonmoralizing possibilities to discuss resistance in practices that apparently conform to dominant discourses demanding assimilation. With regards to Christine Quinan's contribution, we would like to note the future theoretical potential it entails for exploring the conceptual resonance between Muñoz's work and Derridean deconstruction and, perhaps most especially, Derrida's work around hauntology and its relevance for the thought of postcolonial trauma, history, and memory.

If Kirndörfer brings in Kristeva and Quinan brings in Derrida, Tegiye Birey, who provides an intervention on Gilroy's work specifically, adds Lévinas to the issue's theoretical background. Lévinas's work, due to its ethical focus, shares concerns with both psychoanalysis and deconstruction. If we welcome these connections to 
important figures of continental thought much motivated by the philosophical elaboration of negative affect, it is not in order to simply return to what we judge to be a better selection of Western theorists. It is in order to continue to pay attention to texts that would expose the violence within the civilizing discourse of the West and provide us with discursive tools to critique this violence. The articles of the present issue offer an affective critique of conceiving conviviality as simply being in opposition to what negative affects might signify in relation to postcolonial trauma. While the articles here do rely on the theoretical fruits of the affective turn associated with a renewed interest in positive affect, a certain embracement, or reappreciation, of negative affect in envisioning the process of not just enduring but also encountering, communicating, and processing past trauma plays a key role in these texts.

In sum, when Gilroy identifies conviviality by excluding fear, anxiety, and violence from what characterizes this joyous togetherness, negative affect seems to be excised from the vision of how we ought to understand the condition of possibility for an "after" of Empire not predetermined by its traumatic violence. We might think of all this as an affectively understood metropolitan postcoloniality, as a figure animated by heterogenous political discourses on increasing global autocratization, as well as traditional values of capitalism and climate change (suggested by the term "capitalocene"). While the articles in our issue do not cover this wider discursive web of metropolitan postcoloniality, the theoretical intervention their combination offers for elaborating on conviviality may open some ways to extend the discussion to these questions as well.

Christine Quinan's article entitled “Transfilial Negotiations and Palimpsestuous Traces: Queering Postcolonial Memory and Intergenerational Transmission" explores two contemporary narratives of the massacre of Algerians on the streets of Paris on October 17, 1961, an event that the French authorities attempted to coverup at that time. Zineb Sedira's installation, Mother Father and I (2003) and Leila Sebbar's novel, The Seine Was Red (first published in French in 1999, translated to English in 2008) offer alternative ways to remember the event, which Quinan convincingly traces in her contribution. Though foregrounding matrilinear lines of communication, Quinan does not specifically focus on gender but understands queering as a deconstructive practice in a rather broad sense, arguing that to "queer things is to transform them, in ways we cannot anticipate [...]" (Winnubst 2006, pp. 138-139). In this sense, queering is akin to "transfiliation," which Denis Provencher defines as an engagement across generations that "reverse[s] the direction of the transfer of knowledge, tradition, and symbolic heritage" (Provencher 2017, p. 47) through an engagement with oral tradition, literature, film, digital photography, and performance art, among other genres. Reading both the installation and the novel as instances of transfiliation, Quinan's article explores the ways in which these creative works challenge public memories of the Algerian war on the level of narrative and affect.

Both authors Quinan engages with explore intergenerational transmissions of traumatic memories. Born in France to Algerian parents, Zineb Sedira is a Londonbased multimedia artist, whose Mother, Father and I is a creative documentary that exposes the experiences Sedira's parents endured. The artwork is also a personal testimony to the trauma Sedira herself inherited. The installation is, in fact, a 
multi-vocal testimony to the war, which Quinan reads as an instance of "queer orientation" (Ahmed 2006): Sedira's parents speak simultaneously, making it impossible for the spectator to give attention to both stories at the same time, while Sedira's silent listening is projected on the third screen. The installation challenges linear ways of narrating history as it aestheticizes the very inability to witness the trauma, not unlike Leila Sebbar's The Seine Was Red. Sebbar, a French-Algerian author, also engages with intergenerational transmissions of traumatic memories: unaware of her family's participation in the protest, the young protagonist of the novel becomes informed about their story only through a documentary. Aware of the failures of intergenerational communication, then, Sebbar's novel showcases the ways in which the memory of the traumatic event can be recorded through alternative multimedia storytelling, such as documentaries and graffities. This latter, which members of the younger generation utilize, is used as a visible reminder of the violence, a palimpsestuous memory trace inscribed in urban space through which "mnemonic conformity" (Amine 2018) is challenged. This is yet another example of transfiliation, as Quinan points out, since, not unlike the narratives of Zineb Sedira's parents, these urban palimpsests reveal the impossibility of narrating history in a straightforward manner in The Seine Was Red. Furthermore, due to their resolution to dwell in negative affect creatively, the installation and the novel showcase alternative ways to communicate traumatic memories, which Quinan, following in the wake of Ana Dragojlovic, reads as a counter-archival practice.

Aparajita Nanda's contribution, "Of Cityscapes, Affect and Migrant Subjectivities in Kiran Desai's Inheritance of Loss" also engages with the impact of the colonial traumas. As the very title of Desai's 2006 novel indicates, the Inheritance of Loss depicts a deep sense of loss, which leaves its mark on the generations in different ways. The novel portrays the experiences of Jemubhai Patel, an older Indian judge, who has been transformed by a sojourn in Cambridge during the Second World War into a self-hating and aggressive individual, and Biju, a younger man who works as an illegal migrant in New York in the 1980s, which is the period when the narrative is set. As Nanda points out, these characters adopt very different strategies to cope with the experience of becoming "strangers" in the West: while Jemubhai adores the English and learns to feel insignificant as he interiorizes views about his own inferiority, Biju adopts a strategy that is akin to José Esteban Muñoz's concept of "disidentification": a tactic of survival through which minoritarian subjects "neither assimilate nor strictly oppose the dominant regime" (Muñoz 1999, p. 16).

Nanda's article traces the impact of urban locations on the formation of migrant subjectivities on the visceral level, drawing on theories of affect, urban space and hauntology. Not unlike Quinan, she investigates the role of negative affect and the ways in which it is transmitted through intergenerational trauma. However, though exposing unseen injuries caused by colonial violence, it is not the act of dwelling in loss and other negative feelings that help characters resist hegemonic discourses in Desai's novel. Instead, as Nanda argues, it is Muñozian disidentification, a strategy akin to Biju's attitude towards stigmatizing ideologies in the Inheritance of Loss, that offers a more viable approach to cope with the traumas of colonialism and the experience of becoming a stranger in "neocolonial" New York. While Jamubhai identifies with the dominant regime in 
Cambridge, adoring the picture of Queen Victoria and, inevitably, hating himself, Biju's more balanced attitude, which is akin to Bill Ashcroft's notion of a sly and "sophisticated affective response" (Ashcroft 2007, p. 7), showcases a feasible strategy to defy stigmatizing ideologies.

Tegiye Birey's article entitled "Devising Conviviality: Intersubjective Becoming through the Labor of Community-Building" investigates the various roles affect plays in staging migrant narratives through the analysis of theatrical performances as convivial encounters. Based on interviews, participant observation, and critical discourse analysis, her contribution explores the ways in which Malmö Community Theatre functions both as a tool for staging migrant narratives and a catalyst for intersubjective becoming. Relying on, yet also departing from, Emmanuel Levinas' work on intersubjectivity and Gilroy's concept of conviviality, Birey argues that convivial encounters need to be facilitated by different forms of community-building which foster intersubjective encounters. This conviviality, however, far from reflecting the ideology of "happy multiculturalism," needs to be "sustained through the unfolding of alterity rather than the recognition of commonality," as Birey points out.

The concept of devising is central to Birey's argument: defined as the labour of community-building "generated in terms of performative alliances, embodied translations, affective negotiations and resource (re)distribution in convivial encounters," the method can be traced back to the anti-hierarchical mobilizations that took place in London and New York in the 1960s. By embracing improvisation and uncertainty, devising foregrounds the lived experiences and visions of the performers. In order to discuss the innovative potential of encounters, Birey proposes to think of devising together with conviviality. Based on the unexpected, the improvised, and the unforeseen, this method makes space for a "plurality of worlds through the principles of participatory democracy," which is the basis of community-building and intersubjective becoming, as Birey points out. Through the analysis of Dreamlands (2016), Malmö 45 (2018), and To Wait (2018) as ethnographic data, her article showcases how devising facilitates spaces for gendered self-representation, performative alliances, and convivial encounters with the world of others.

Elisabeth Kirndörfer's contribution, "Polic(sh)ing up the Leipzig Main Station: An Ethnographic Reflection on Abjection, Space and Resistance" focuses on the moment when the Leipzig Main Station was transformed into a site of protest by immigrants from North and Southwest Africa and their German-born allies in November 2017. Kirndörfer relies on content analysis approach and critical discourse analysis to discuss ethnographic material that shed light on the formation of migrant subjectivities. Participant observations, explorative walks, conversations, and interviews help her investigate how the station turned into a symbol for the loss of state control during the "refugee crisis." Julia Kristeva' a concept of abjection is particularly significant for her argument as it helps to explore how "social abjection" may initiate attempts to re-appropriate space. Understanding abjection in spatial terms as an "overlap zone" (England 2008; Sharkey and Shields 2008), defined as a domain that is constitutive for the formation of the subject, Kirndörfer explores the production of "urban abjects," stigmatized as strange bodies out of place (Ahmed 2006), vis-a-vis a normative urban centre perceived as clear, ordered, and white. 
Kirndörfer is also interested in the inner fractions that characterize protest action, which she investigates through the ethnographic analysis of plays and protest marches. The play "Borders," for instance, which is performed as part of a protest action at the Hauptbahnhof, tells the story of Sami, who reaches Europe after a long period full of hope and anxiety. She defines resistance as an action that is disruptive, affective, and fractured, and which is stimulated by the very politics of abjection. Resistance in general, and protest action in particular, irritate mainstream discourses by "positioning abject beings as active citizens who decide upon their lives and articulate their stories in public." Drawing on Butler's and Gilroy's theories (Gilroy 2004; Butler 1993), Kirndörfer reads protest as a solidary and convivial action, which may be defined as a politics of difference intertwined with the racializing workings of European (post)colonial powers (Gilroy 2004). One of the best examples of conviviality is the moment when protest action turns into a party at the Hauptbahnhof, which is the very moment when ethnic difference becomes insignificant yet the "shared consciousness of the workings of European racism that produces difference" remains visible, as Kirndörfer argues.

How to live together convivially "after Empire," then? How to reframe "the stranger" in ways that not only challenge the discourses that produce this stigmatized image but also offer viable alternatives? The articles in this special issue start to answer these questions as they, inevitably, raise others while exploring the legacy of colonialism and hegemonic ideologies that dominate "neocolonial" cities. Tracing the complex role affective exchange plays in producing subjectivities, they foreground alternative, "affective" modes of knowing the world, and open, we hope, avenues for future research.

\section{References}

Ahmed, S. 2000. Strange Encounters. London: Routledge.

Ahmed, S. 2004. Affective Economies. Social Text 22 (2): 117-139.

Ahmed, S. 2006. Queer Phenomenology: Orientations, Objects, Others. Durham: Duke University Press.

Amine, L. 2018. Postcolonial Paris: Fictions of Intimacy in the City of Light. Madison: University of Wisconsin Press.

Ashcroft, B. 2007. Post-Colonial Studies: The Key Concepts. New York: Routledge.

Blackman, L., J. Cromby, D. Hook, D. Papadopoulos, and V. Walkerdine. 2008. Editorial: Creating Subjectivities. Subjectivity 22: 1-27.

Braidotti, R. 2006. Affirming the Affirmative: On Nomadic Affectivity. Rhizomes 11/12. http://www. rhizomes.net/issue11/braidotti.html

Butler, J. 1993. Bodies that Matter. New York: Routledge.

Dragojlovic, A. 2018. Politics of Negative Affect: Intergenerational Hauntings, Counter-Archival Practices and the Queer Memory Project. Subjectivity 11 (4): 91-107.

England, M. 2008. Stay Out of Drug Areas: Drugs, Othering and Regulation of Public Space in Seattle, Washington. Space and Polity 12 (02): 197-213.

Gilroy, Paul. 2004. After Empire: Melancholia or Convivial Culture? London: Routledge.

McLeod, John. 2004. Postcolonial London: Rewriting the Metropolis. London: Routledge.

Muñoz, José Esteban. 1999. Disidentifications: Queers of Color and the Performance of Politics. Minnesota: University of Minnesota Press.

Provencher, Denis M. 2017. Queer Maghrebi French: Language, Temporalities, Transfiliations. Liverpool: Liverpool University Press. 
Sharkey, A., and R. Shields. 2008. Abject Citizenship-Rethinking Exclusion and Inclusion: Participation, Criminality and Community at a Small Town Youth Centre. Children's Geographies 6 (3): 239-256.

Varma, Rashmi. 2012. The Postcolonial City and its Subjects: London, Nairobi, Bombay. London: Routledge.

Winnubst, Shanon. 2006. Queering Freedom. Bloomington: Indiana University Press.

Publisher's Note Springer Nature remains neutral with regard to jurisdictional claims in published maps and institutional affiliations.

Ágnes Györke is Associate Professor of English at Károli Gáspár University's Institute of English Studies in Budapest, Hungary. She has been a visiting scholar at Indiana University, the University of Leeds, the University of Bristol, King's College London, and research fellow at Central European University's Institute for Advanced Study. Her recent publications include Geographies of Affect in Contemporary Literature and Visual Culture (co-editor, Brill 2021) and "On the Periphery: Contemporary Exile Fiction and Hungary" (Journal of Postcolonial Writing, 2021).

Eszter Timár is Assistant Professor of Gender Studies at Central European University. Her research draws on deconstruction, feminist new materialism and queer theory. She writes on deconstruction, queer theory, affect theory and biology (especially immunology). 